\title{
High incidence of ace-1 duplicated haplotypes in resistant Culex pipiens mosquitoes from Algeria
}

\author{
Haoues Alout*, Pierrick Labbé, Nicole Pasteur, Mylène Weill \\ Team Genetic of Adaptation, Laboratoire Génétique et Environnement, CNRS UMR 5554, Institut des Sciences de l'Evolution, \\ Université Montpellier 2, Place E. Bataillon, 34095 Montpellier cedex 05, France
}

\section{A R T I C L E I N F O}

\section{Article history:}

Received 3 July 2010

Received in revised form

14 September 2010

Accepted 17 September 2010

\section{Keywords:}

Insecticide resistance

ace-1 duplication

Culex pipiens

\begin{abstract}
A B S T R A C T
The status of genes conferring resistance to organophosphate and carbamate insecticides has been examined in Culex pipiens pipiens mosquitoes sampled in Algeria. Presence of overproduced esterases was sporadic, but acetylcholinesterase-1 resistant alleles were observed in almost all samples. We focused our study on the AChE1 G119S substitution characterized in almost all samples, mostly at the heterozygous state. A genetic test revealed the presence of ace-1 duplication associating a susceptible and a resistant ace-1 copy. Molecular characterization showed a high occurrence of ace-1 duplication with six distinct duplicated alleles out of four samples. The inferred frequency of duplicated allele suggests that it is replacing the single resistant G119S allele. Finally, we discuss the mechanism at the origin of these duplicated haplotypes and their consequences on the management of insecticide resistance.
\end{abstract}

(c) 2010 Elsevier Ltd. All rights reserved.

\section{Introduction}

A new adaptive mutation is often associated with negative side effects that may be reduced with time by the selection of compensatory mutations (or modifiers; Fisher, 1958) or by the replacement with less deleterious alleles (Haldane, 1932). Such evolutionary processes have been documented in two studies related to insecticide resistance. The first example is the resistance to diazinon in the blowfly Lucilia cuprina (McKenzie and Game, 1987; McKenzie, 1993) and the other is the resistance to organophosphate (OP) and carbamate (CX) insecticides in Culex pipiens mosquitoes (Guillemaud et al., 1998).

Due to mosquito control with OP in Southern France, two main resistance mechanisms have been selected in C. pipiens pipiens and the polymorphism of the genes involved has been regularly monitored over the last 40 years (reviewed in Raymond et al., 2001; Weill et al., 2005; Labbé et al., 2007b). One resistance mechanism involves the super-locus Ester, which codes detoxifying carboxylesterases. Resistant mosquitoes overproduce these enzymes, either through up-regulation or through gene amplification, and several Ester alleles have been selected over time, each conferring a different resistance ratio to OP and being associated with a specific fitness cost (Guillemaud et al., 1998; Raymond et al.,

\footnotetext{
* Corresponding author. Fax: +33 (0)4 67143622 .

E-mail address: haoues.alout@univ-montp2.fr (H. Alout).
}

2001; Berticat et al., 2002a,b, 2004; Duron et al., 2006; Labbé et al., 2009). Evolution at the Ester locus was shown to proceed by allele replacement (Guillemaud et al., 1998; Labbé et al., 2009). The other resistance mechanism involves a modification of the gene ace-1 coding for the acetylcholinesterase- 1 enzyme (AChE1), the target of $\mathrm{OP}$ and $\mathrm{CX}$ insecticides. The first resistant ace-1 allele (ace $-1^{R}$, abbreviated $\mathrm{R}$ in this paper) resulted from a single amino acid substitution, G119S (Weill et al., 2003). This point mutation confers high resistance to CX and OP, but exhibits strong pleiotropic effects in the absence of insecticide, as revealed by the clinal pattern of its frequency between treated and non-treated areas around Montpellier (Lenormand et al., 1999). The G119S mutation, located in the AChE1 active site prevents inhibition by OP but also interferes with substrate binding, resulting in a reduction of AChE1 activity (Alout et al., 2008). This reduction may account, at least in part, for the reduced fitness observed in mosquitoes homozygous for the G119S AChE1 substitution (Berticat et al., 2002a,b, 2004; Bourguet et al., 2004; Duron et al., 2006). A second ace-1 allele (or haplotype) was later selected. It originated from a duplication of the ace- 1 gene (named ace- $1^{D}$ or $\mathrm{D}$ ), associating a susceptible and a resistant copy (named $D(S)$ and $D(R)$, respectively), hence producing "permanent heterozygotes", and behaving as a new allele (Labbé et al., 2007a). In Montpellier area, this duplicated haplotype also displays a frequency cline between treated and nontreated areas, indicating a fitness cost relative to the susceptible allele ( $a c e-1^{S}$, abbreviated $S$ thereafter). However, the D allele has partially replaced the $\mathrm{R}$ allele: the ace-1 duplication seems to be 
more advantageous by maintaining resistance while restoring part of the fitness of R allele (Lenormand et al., 1998a; Labbé et al., 2007a,b).

Another mutation (F290V, named V here) has recently been identified at the ace-1 locus of $C$. $p$. pipiens mosquitoes from Mediterranean countries, and also occurs in duplicated ace-1 haplotypes (Alout et al., 2007, 2009). This mutation confers distinct levels of insensitivity toward various OP and CX insecticides (Alout and Weill, 2008) but seems also costly; however biochemical analyses revealed that this cost is not associated with AChE1 activity reduction.

In this paper, we have examined the CX and OP resistance status of Culex $p$. pipiens mosquitoes sampled in nine breeding sites from Algeria. Several Ester and ace-1 alleles were observed. Here, we particularly focused on the resistant ace-1 alleles associated with the G119S mutation only, as data concerning the F290V associated allele are reported elsewhere in relation to other such alleles in the Mediterranean region (Alout et al., 2009). Presence of the G119S mutation was recorded in almost all samples, mostly at the heterozygous state. Crossing experiments revealed the presence of ace-1 duplication containing a susceptible copy $(\mathrm{S})$ and a resistant $(\mathrm{R})$ copy in all the samples studied, and sequencing of the ace-1 copies identified six different duplicated haplotypes. The whole data set on CX and OP resistance genes observed in Algerian C. p. pipiens is discussed in relation to the management of insecticide resistance.

\section{Materials and methods}

\subsection{Mosquito samples and strains}

Culex p. pipiens larvae were collected from nine breeding sites in Algeria (Fig. 1). Samples from Zitoun, Tafna, Smar, Harash and Constantine were collected in 2006, those from Guelma, Douas, Kala and Lac des oiseaux were collected in 2008. All sites sampled were epigeous except the Kala sample, which was hypogeous. Adults emerging from field-collected larvae were stored in liquid nitrogen for further analyses. Four collections (Tafna, Smar, Harash, and Constantine) were allowed to reproduce in the laboratory and their progenies were used for founding strains. Several C. pipiens reference strains were used in the experiments: the susceptible strain Slab (Georghiou et al., 1966) lacking any resistant gene; SR and Homoval strains, both lacking overproduced esterase but respectively homozygous for the G119S (Berticat et al., 2002a) and F290V mutations (Alout et al., 2009) at the ace-1 locus; SA1, SA2, SA4, SB1 and TunB12 strains, which are homozygous for Ester ${ }^{1}$, Ester $^{2}$, Ester $^{4}$ $E_{\text {Ester }}{ }^{B 1}$ and Ester ${ }^{B 12}$ alleles, respectively (Berticat et al., 2002a; Ben Cheikh et al., 2008), and all susceptible at the ace-1 locus.

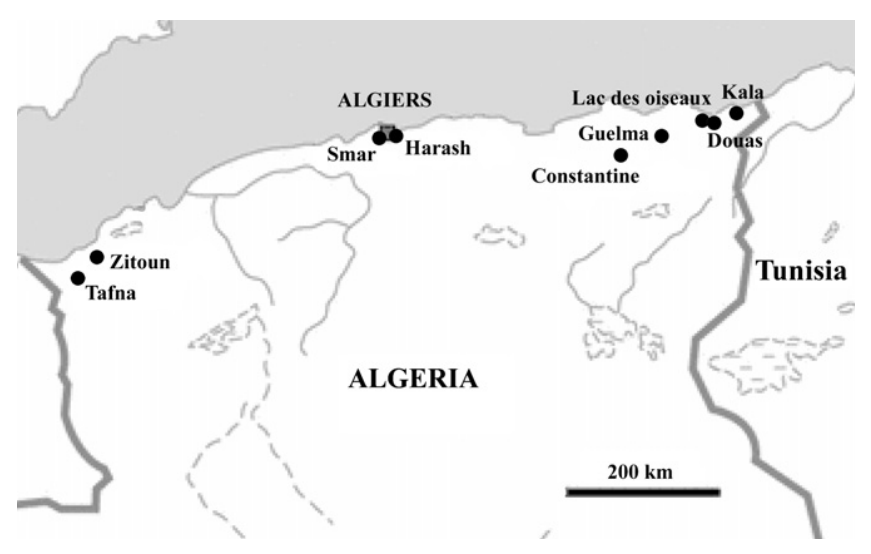

Fig. 1. Culex p. pipiens larvae sampling sites in Algeria.
When necessary, Slab strain was cured of Wolbachia infection to avoid cytoplasmic incompatibilities during crosses (Yen and Barr, 1973). To this effect, larvae were reared in water containing tetracycline hydrochloride $(20 \mathrm{mg} / \mathrm{l}$, Sigma-Aldrich) for three generations and were used to found the SlabTC strain (Duron et al., 2006).

\subsection{Identification of overproduced esterases}

Esterase phenotypes were investigated by starch gel electrophoresis in Tris-Maleate buffer-EDTA (pH 7.4) as described by Pasteur et al. (1988). Briefly, $\alpha$ - and $\beta$ - esterase enzyme from homogenates of individual thorax were separated and revealed using $\alpha$ - and $\beta$-naphthyl acetates and Fast Garnett. Allele identification was performed by comparing the electrophoretic mobility of esterases from strains homozygous for the different resistant Ester alleles (nota: for a same amplified Ester allele, the gene amplification level can vary while the sequence remains identical, Weill et al., 2000; Guillemaud et al., 1997). Ester ${ }^{4}$ and $E s t e r^{5}$ alleles code enzymes with a similar electrophoretic mobility (Poirié et al., 1992); they were discriminated using the PCR-RFLP test developed by Berticat et al. (2000).

\subsection{TDP ("Témoin Dichlorvos Propoxur") biochemical test}

AChE1 enzymatic phenotypes were analyzed with the TDP test described by Alout et al. (2009). It allows identifying susceptible mosquitoes as well as resistant ones, and discriminates between those carrying the R (G119S) or the V (F290V) mutations at the ace1 locus. Enzymatic phenotypes are named according to the AChE1 variants they contain, i.e. [SS], [RR], [VV], [RS], [VS], [VR], or [VRS]. Briefly, each mosquito head was homogenized in $400 \mu \mathrm{l}$ of $0.25 \mathrm{M}$ phosphate buffer containing $1 \%$ Triton X-100. The homogenate was centrifuged at $9000 \mathrm{~g}$ for $3 \mathrm{~min}$, and $100 \mu \mathrm{l}$ of supernatant were distributed into three wells of a 96-well microtiter plate; $10 \mu \mathrm{l}$ of ethanol (95\%), $10 \mu \mathrm{l}$ of $5 \times 10^{-5} \mathrm{M}$ dichlorvos, and $10 \mu \mathrm{l}$ of $10^{-1} \mathrm{M}$ propoxur were added to the first, second and third well, respectively. After $15 \mathrm{~min}$ of incubation, $100 \mu \mathrm{l}$ of acetylthiocholine substrate at a concentration of $1.6 \mathrm{mM}$ were added. Rate of reaction was measured at $412 \mathrm{~nm}$ during 15 min with a microtiter plate reader (Biotek, Winooski, VT).

\subsection{Detection of ace-1 gene duplications}

Two independent analyses were performed. The first was based on crossing experiments as follows. The progenies of Tafna, Smar, Harash and Constantine strains were selected using a 24-h exposure of $1 \mathrm{mg} / \mathrm{l}$ propoxur insecticide (a dose that kills only susceptible [SS] individuals) during three generations. Resistant females of each strain were then crossed with susceptible SlabTC males. After fecundation and blood feeding, females of each strain were isolated individually to produce egg rafts and then stored in liquid nitrogen. Each progeny was reared separately and second instar larvae were exposed to $1 \mathrm{mg} / \mathrm{l}$ propoxur during $24 \mathrm{~h}$. Females with progenies displaying no mortality were analyzed with the TDP test. If they display a heterozygous phenotype, either [RS] or [VS], then they carry at least one ace-1 duplicated gene (see Labbé et al., 2007a).

The second analysis was based on a statistical inference. Phenotypic data of each field sample were fitted independently to two distinct models: a 2-alleles model, with the $\mathrm{R}$ and $\mathrm{S}$ alleles only, and a 3-alleles model, with R, S and the duplicated haplotype D. The presence of such a duplicated haplotype is expected to create an excess of [RS] phenotypes in panmictic populations. This excess can then be used to estimate the frequency of ace-1 duplication (Lenormand et al., 1998a; Labbé et al., 2007b; Djogbénou et al., 2009). For each sample, expected phenotypic distributions were 
computed using allelic frequencies estimated by the 2- and 3alleles models, assuming ace-1 locus to be at Hardy-Weinberg equilibrium. The phenotype was considered to be a three-state random variable ([RR], [RS] and [SS]). The log-likelihood of the phenotypic distribution observed in a sample was computed, for each model, as:

$L_{i}=\sum_{i} n_{i j} \ln \left(f_{i j}\right)$

where $n_{i j}$ and $f_{i j}$ are the observed number and expected frequency of phenotype $i$ in population $j$, respectively. It was maximized using the Metropolis algorithm (see Lenormand et al., 1999, 1998b; Lenormand and Raymond, 2000). Two- and 3-alleles model likelihoods of each sample were compared using F-tests: by construction the 3-alleles model has a higher likelihood, but the presence of the duplication was considered validated when this likelihood was significantly higher than that of the 2-alleles model. The support limits for the frequency of the resistant and the duplicated haplotype ( $R$ and $D$, respectively) were also estimated.

\section{5. ace-1 sequencing}

Total DNA was extracted using a CTAB protocol (Rogers and Bendich, 1988). In this study, we focused only on G119S associated alleles, then part of ace-1 gene comprising the end of exon 2, the following intron 2 and exon 3 was amplified using specific primers: Intron2dir 5'-GCG CGA GCA TAT CCA TAG CAC T-3' and CpEx3rev 5'-GAC TTG CGA CAC GGT ACT GCA-3', generating a $588 \mathrm{bp}$ fragment. PCR was run for 30 cycles $\left(94{ }^{\circ} \mathrm{C}\right.$ for $30 \mathrm{~s}, 52^{\circ} \mathrm{C}$ for $30 \mathrm{~s}$, and $72^{\circ} \mathrm{C}$ for $30 \mathrm{~s}$ ). PCR products were purified with the QIAquick gel extraction kit (QIAGEN). Sequences of ace-1 G119S from homozygous [RR] field mosquitoes were performed directly on purified PCR products. For each strain (Tafna, Smar, Harash and Constantine), sequences of duplicated haplotypes were acquired from four [RS] females that were shown to contain the duplication in the crossing experiments ( 16 females sequenced in total). PCR products were cloned to separate the different copies, using the TOPO ${ }^{\circledR}$ TA Cloning Kit (Invitrogen), according to the manufacturer's instructions. Clones were screened to discriminate susceptible and G119S resistant copies by PCR using the same primers followed by Alul digestion (Weill et al., 2004). For each female, 6 susceptible and 6 resistant clones were sequenced, to avoid Taq polymerase misreading, on an ABI Prism 310 sequencer using the Big Dye terminator kit (Applied Biosystems).

\subsection{Sequence analysis}

Sequences were aligned using the Multalin software (http:// prodes.toulouse.inra.fr/multalin/multalin.html; Corpet, 1988). The similarity between the various sequences was assessed with ClustalW (Neighbor-Joining method, v1.83, http://www.ddbj.nig.ac.jp/ search/clustalw-e.html, Thomopson et al., 1994). Deduced amino acid sequences were obtained with ClustalW to determine whether the mutations identified were synonymous or non-synonymous. We investigated the position of each non-synonymous mutation in a model of $C$. pipiens AChE1 3D structure (Weill et al., 2004), using PyMOL 0.99rc6 (Delano Scientific LLC).

\section{Results}

\subsection{Resistance gene status of field samples}

Mosquitoes were sampled in nine breeding sites of Algeria in a $75 \mathrm{~km}$-wide area along the Mediterranean coast, extending from the western to the eastern borders (Fig. 1). They were analyzed for the presence of overproduced esterases and AChE1 substitutions.

A total of four resistant Ester phenotypes ([Ester $\left.{ }^{1}\right],\left[\right.$ Ester $\left.^{2}\right]$, $\left[\right.$ Ester $\left.^{4}\right]$ and $\left[\right.$ Ester $\left.\left.^{B 12}\right]\right)$ were observed in six of the nine samples (Table 1), with the frequency of carriers not exceeding $36 \%$ and no mosquito displaying simultaneously two overproduced enzymes. Identification of Ester ${ }^{4}$ allele was confirmed by PCR-RFLP in four individuals from Tafna and Zitoun and in two individuals from Kala (see Materials and Methods). Overall, Ester ${ }^{1}$ and Ester $^{B 12}$ carriers are relatively rare, whereas Ester ${ }^{4}$ and Ester ${ }^{2}$ carriers have variable frequencies and both can reach $21 \%$ in some populations.

Insensitive AChE1 was observed in almost all samples, and the two substitutions responsible for resistance, G119S and F290V were present (Table 2). The F290V mutation is very rare in the central and the eastern part of the country with only one carrier in three samples, while near the west border (Tafna and Zitoun) higher frequencies were observed. Detailed results concerning this mutation are reported elsewhere (Alout et al., 2009). In contrast, the G119S mutation was found in almost all samples. The [RS] phenotype was the most abundant with frequencies above $60 \%$ in four samples (Smar, Harash, Guelma and Kala). The [RR] phenotype was rare or absent, except in Kala where its frequency reached $17 \%$.

\subsection{Evidence for ace-1 duplication}

The high frequency of [RS] phenotypes in some samples suggested that the ace-1 locus might be duplicated in Algerian populations, as found in many other countries (Lenormand et al., 1998a; Labbé et al., 2007a). In order to test this hypothesis, we searched evidence for duplicated haplotypes by crossing experiments, following the procedure used by Labbé et al. (2007a). Several heterozygous [RS] females from the strains derived from Tafna, Smar, Harash and Constantine field samples were crossed with a susceptible SlabTC male and displayed a progeny all resisting the propoxur exposure (see Materials and Methods). This result shows that at least one duplicated ace-1 haplotype (D) associating a susceptible copy $D(S)$ with a G119S $D(R)$ copy is present in the four strains.

The presence of a duplicated haplotype (D) in field samples is likely to explain the high frequency of [RS] phenotypes observed in some populations (Table 2). The statistical inference designed to test this assumption compares the observed phenotypic frequencies with those expected either in absence or in presence of a duplicated haplotype (excluding Tafna and Zitoun in which [VS] and [VRS] enzymatic phenotypes had a frequency of $\sim 12 \%$, which precludes a robust analysis, Table 2). Although this method is not as accurate as direct observation of the different genotypes, it has been shown to correctly estimate the duplication frequency in field samples where this frequency was independently estimated using

Table 1

Frequency of the various overproduced esterase phenotypes in the populations sampled. $N$ is the number of individuals analyzed. The frequency of each phenotype is given, together with the corresponding number of individuals indicated in brackets.

\begin{tabular}{lllllll}
\hline Sample name & $N$ & \multicolumn{6}{l}{ Observed overproduced esterase phenotypes } \\
\cline { 3 - 7 } & & None & {$\left[\right.$ Ester $\left.^{1}\right]$} & {$\left[\right.$ Ester $\left.^{2}\right]$} & {$\left[\right.$ Ester $\left.^{4}\right]$} & {$\left[\right.$ Ester $\left.^{\text {B12 }}\right]$} \\
\hline Tafna & 38 & $0.75(29)$ & 0 & 0 & $0.21(8)$ & $0.04(2)$ \\
Zitoun & 50 & $0.64(32)$ & 0 & $0.12(6)$ & $0.20(18)$ & $0.04(2)$ \\
Smar & 32 & $1.00(32)$ & 0 & 0 & 0 & 0 \\
Harash & 50 & $0.96(48)$ & $0.04(2)$ & 0 & 0 & 0 \\
Constantine & 17 & $1.00(17)$ & 0 & 0 & 0 & 0 \\
Guelma & 29 & $0.97(28)$ & 0 & $0.03(1)$ & 0 & 0 \\
Lac des oiseaux & 48 & $0.90(43)$ & 0 & $0.10(5)$ & 0 & 0 \\
Douas & 58 & $1.00(58)$ & 0 & 0 & 0 & 0 \\
Kala & 29 & $0.72(21)$ & 0 & $0.21(6)$ & $0.07(2)$ & 0 \\
\hline
\end{tabular}


Table 2

Frequency of AChE1 enzymatic phenotypes in Algerian field samples (adapted from Alout et al., 2009, where only the F290V mutation data were published). N is the number of individuals analyzed. S, R and V represent the AChE1 susceptible, the G119S and the F290V mutations, respectively. Frequency of each phenotype is indicated, together with the corresponding number of individuals indicated in brackets.

\begin{tabular}{|c|c|c|c|c|c|c|c|c|}
\hline \multirow[t]{2}{*}{ Sample name } & \multirow[t]{2}{*}{$\mathrm{N}$} & \multicolumn{7}{|c|}{ AChE1 phenotypes (TDP test) } \\
\hline & & {$[\mathrm{SS}]$} & [RS] & [RR] & {$[\mathrm{VV}]$} & [VS] & [VR] & [VRS] \\
\hline Tafna & 38 & $0.46(17)$ & $0.25(10)$ & $0.04(1)$ & 0 & $0.12(5)$ & 0 & $0.12(5)$ \\
\hline Zitoun & 50 & $0.88(44)$ & 0 & 0 & 0 & $0.04(2)$ & 0 & $0.08(4)$ \\
\hline Smar & 32 & $0.34(11)$ & $0.66(21)$ & 0 & 0 & 0 & 0 & 0 \\
\hline Harash & 50 & $0.24(12)$ & $0.66(33)$ & $0.08(4)$ & 0 & $0.02(1)$ & 0 & 0 \\
\hline Constantine & 17 & $0.71(12)$ & $0.29(5)$ & 0 & 0 & 0 & 0 & 0 \\
\hline Guelma & 29 & $0.21(6)$ & $0.72(21)$ & $0.03(1)$ & 0 & $0.03(1)$ & 0 & 0 \\
\hline Lac des oiseaux & 48 & $0.75(36)$ & $0.23(11)$ & 0 & 0 & $0.02(1)$ & 0 & 0 \\
\hline Douas & 58 & $1(58)$ & 0 & 0 & 0 & 0 & 0 & 0 \\
\hline Kala & 29 & $0.21(6)$ & $0.62(18)$ & $0.17(5)$ & 0 & 0 & 0 & 0 \\
\hline Total number & 351 & 202 & 119 & 11 & 0 & 10 & 0 & 9 \\
\hline
\end{tabular}

crosses (Lenormand et al., 1998a). We found that observed phenotypic frequencies is best explained by the presence of a $D$ allele in three samples: Smar and Harash (where a D allele was also detected by crossing experiments) and Guelma. The frequency of the D allele is predicted to be $41 \%$ in Smar, $21 \%$ in Harash and $32 \%$ in Guelma (Table 3). The presence of the D allele cannot be confirmed from the phenotypic frequencies in other samples, as the differences between the models with and without $D$ are not statistically significant. However, the ace-1 duplication was shown to be present when sequencing resistant mosquitoes in Constantine. This discrepancy between statistical inference and direct sequencing is probably due to a yet too low frequency of the duplicated haplotype in this locality.

\subsection{Characterization of duplicated ace-1 haplotypes}

A fragment of the ace-1 gene encompassing the G119S mutation was amplified in four [RS] females per strain analyzed carrying the duplication detected by crossing experiments. Susceptible $D(S)$ and resistant $\mathrm{D}(\mathrm{R})$ copies were cloned and sequenced (Table 4). All $\mathrm{D}(\mathrm{R})$ copies were identical to the single $R$ sequence present in homozygous resistant [RR] insects of each sample (when present) and to the $C . p$. pipiens subspecies sequence previously described (Weill et al., 2003). The $R$ sequence is also identical to the $\mathrm{D}(\mathrm{R})$ copy identified in duplicated C. p. pipiens haplotypes from France (Labbé et al., 2007a), indicating a single evolutionary origin for the G119S mutation in this subspecies. $\mathrm{D}(\mathrm{S})$ sequences were numbered according to Labbé et al. (2007a) nomenclature, and since all were different from those already described, numbering began at $D_{7}(S)$. In the four females of the Tafna strain, only one susceptible sequence $\left(D_{7}(S)\right)$ was identified. In females from Smar, two different $\mathrm{D}(\mathrm{S})$ sequences were observed; one differs from the $D(R)$ sequence by the G119S mutation only and was named $D_{8}(S)$, the other was a new sequence and was named
$D_{9}(S)$. In Harash sample, we found also two different $D(S)$ sequences: one identical to the $D_{9}(S)$ sequence, the other new and named $D_{10}(S)$. Finally in females from Constantine, there were two distinct $D(S)$ sequences highly different from one another and from the others; they were named $D_{11}(S)$ and $D_{12}(S)$. Thus the four Algerian samples tested contained 6 new duplicated haplotypes $\left(D_{7}\right.$ to $\left.D_{12}\right)$, with only one of them being observed in two locations ( $D_{9}$ in Smar and Harash). They all differ by at least 6 synonymous mutations except in the D7S copy from Tafna and D10S from Harash where the C95R and R104K substitutions were identified. They are located on a flexible loop at the periphery of the enzyme (at some distance from the active site) and are therefore unlikely to interfere with the catalytic properties (data not shown).

Sequence of duplicated ace-1 D haplotypes from Algeria were compared with those described by Labbé et al. (2007a) from different parts of the world by constructing a genetic distance tree of $\mathrm{D}(\mathrm{R})$ and $\mathrm{D}(\mathrm{S})$ sequences (Fig. 2). Samples from Martinique, Cuba and Philippines (named Mart, Cuba and Pal, respectively) belong to the subspecies Culex p. quinquefasciatus, whereas all the others, from southern France and Algeria, belong to the Culex p. pipiens subspecies. The ace-1 sequences observed in C. p. pipiens differ by an 8bp deletion in the intron-2 sequence as compared to C. p. quinquefasciatus (Labbé et al., 2007a). Thus, as expected, ace-1 sequences found in Algeria cluster with those of French C. p. pipiens. In France and Algeria, all D(R) sequences are identical, but all $\mathrm{D}(\mathrm{S})$ sequences differed and their differentiation does not display any particular geographic pattern.

\section{Discussion}

In this study, we identified two mechanisms responsible for resistance to organophosphate insecticides in the $C$. $p$. pipiens mosquitoes from Algeria: overproduction of detoxifying esterases encoded by the Ester superlocus and insensitive

Table 3

Theoretical allele frequencies in presence or absence of a duplicated haplotype (D). pS, pR and pD are the estimated frequencies of the susceptible, the resistant G119S and the duplicated alleles, respectively ( $\mathrm{pS}=1-\mathrm{pR}-\mathrm{pD}$ ). F-test statistics comparing the likelihoods of the two models (see material and methods), and the corresponding $p$-value for each sample are indicated. Presence of duplication is assumed from the phenotypic data when the likelihood of the 3-alleles model is significantly higher than that of the 2alleles model (bolded $p$-value).

\begin{tabular}{|c|c|c|c|c|c|c|c|c|c|c|}
\hline \multirow[t]{2}{*}{ Sample name } & \multicolumn{2}{|c|}{ Without D } & \multicolumn{5}{|c|}{ With D } & \multirow[t]{2}{*}{$F$-test value } & \multirow[t]{2}{*}{$p$-value } & \\
\hline & $\mathrm{pR}$ & $\mathrm{pS}$ & PR & Support limits & PD & Support limits & $\mathrm{pS}$ & & & \\
\hline Harash & 0.41 & 0.59 & 0.28 & $(0.16-0.42)$ & 0.21 & $(0.08-0.47)$ & 0.51 & 6.97 & 0.008 & ** \\
\hline Smar & 0.33 & 0.67 & 0 & $(0-0.24)$ & 0.41 & $(0.18-0.56)$ & 0.59 & 10.71 & 0.001 & $* * *$ \\
\hline Lac des oiseaux & 0.11 & 0.89 & 0 & $(0-0.17)$ & 0.12 & $(0-0.2)$ & 0.88 & 1.43 & 0.232 & NS \\
\hline Kala & 0.48 & 0.52 & 0.42 & $(0.25-0.58)$ & 0.13 & $(0-0.51)$ & 0.45 & 1.73 & 0.189 & NS \\
\hline Douas & 0.25 & 0.75 & 0.25 & $(0.18-0.33)$ & 0 & $(0-0.03)$ & 0.75 & 0 & 1 & NS \\
\hline Guelma & 0.4 & 0.6 & 0.19 & $(0.04-0.38)$ & 0.32 & $(0.04-0.38)$ & 0.49 & 8.6 & 0.003 & $* *$ \\
\hline Constantine & 0.15 & 0.85 & 0 & $(0-0.27)$ & 0.16 & $(0-0.3)$ & 0.84 & 0.87 & 0.352 & NS \\
\hline
\end{tabular}


Table 4

Sequence alignment of partial ace-1 copies of $C$. p. pipiens duplicated haplotypes. The C. p. pipiens G119S allele sequence (Weill et al., 2003) is used as the reference sequence ( $\mathrm{R}$ copy). Polymorphism is indicated for the $\mathrm{D}(\mathrm{R})$ and $\mathrm{D}(\mathrm{S})$ copies of each duplicated haplotype ace- $1^{\mathrm{D}}$. The positions are numbered from the first nucleotide of intron 2 and of exon 3 and the dash $(-)$ indicates identity and star $\left(^{*}\right)$ indicates deletion. The mutation at position 361 (highlighted) is the only mutation conferring resistance (G119S).

\begin{tabular}{|c|c|c|c|c|c|c|c|c|c|c|c|c|c|c|c|c|c|c|c|c|c|c|c|c|c|c|c|c|c|c|c|c|c|c|}
\hline & \multicolumn{13}{|c|}{ Intron 2} & \multicolumn{21}{|c|}{ Exon 3} \\
\hline & & & & & & & & & & & & & & & & 1 & 1 & 1 & 2 & 2 & 2 & 3 & 3 & 3 & 3 & 3 & 3 & 3 & 3 & 3 & 3 & 4 & 4 & 4 \\
\hline & 1 & 2 & 3 & 3 & 3 & 3 & 3 & 3 & 3 & 3 & 4 & 4 & 4 & & 8 & 5 & 5 & 9 & 2 & 8 & 9 & 1 & 1 & 1 & 1 & 2 & 3 & 5 & 6 & 6 & 9 & 0 & 2 & 2 \\
\hline & 5 & 7 & 1 & 2 & 3 & 4 & 6 & 7 & 8 & 9 & 1 & 2 & 5 & 9 & 1 & 0 & 3 & 5 & 5 & 6 & 1 & 3 & 4 & 5 & 8 & 4 & 6 & 4 & 1 & 3 & 9 & 2 & 0 & 6 \\
\hline $\mathrm{R}$ & $\mathrm{T}$ & A & C & $\mathrm{C}$ & $\mathrm{C}$ & & $\mathrm{T}$ & $\mathrm{T}$ & G & C & A & A & A & C & G & G & A & A & C & $\mathrm{T}$ & G & A & G & G & G & C & $\mathrm{T}$ & $\mathrm{T}$ & A & C & $\mathrm{T}$ & $\mathrm{T}$ & G & C \\
\hline $\mathrm{D}(\mathrm{R})$ & - & - & - & - & - & - & - & - & - & - & - & - & - & - & - & - & - & - & - & - & - & - & - & - & - & - & - & - & - & - & - & - & - & - \\
\hline From France & & & & & & & & & & & & & & & & & & & & & & & & & & & & & & & & & & \\
\hline $\mathrm{D}_{2}(\mathrm{~S})$ Maurin & - & - & - & - & - & $\mathrm{C}$ & - & $\mathrm{C}$ & - & - & - & - & - & $\mathrm{T}$ & A & - & $\mathrm{T}$ & G & - & - & - & C & - & - & - & - & $\mathrm{C}$ & - & G & - & C & - & - & - \\
\hline $\mathrm{D}_{3}(\mathrm{~S})$ Biface & - & - & - & - & - & - & - & - & - & - & - & - & G & - & - & - & - & C & - & - & - & C & - & - & C & - & C & - & G & A & C & $\mathrm{C}$ & - & $\mathrm{T}$ \\
\hline $\mathrm{D}_{6}(\mathrm{~S})$ Dumont & - & - & - & - & - & - & - & - & - & - & - & - & - & - & A & - & $\mathrm{T}$ & G & - & & - & C & - & - & - & - & C & - & G & - & C & - & - & - \\
\hline From Algeria & & & & & & & & & & & & & & & & & & & & & & & & & & & & & & & & & & \\
\hline $\mathrm{D}_{7}(\mathrm{~S}) \mathrm{Tafna}$ & - & - & - & - & - & - & - & - & - & - & - & - & - & - & - & A & - & - & A & - & - & - & A & A & $\mathrm{C}$ & A & $\mathrm{C}$ & C & G & - & C & C & - & $\mathrm{T}$ \\
\hline $\mathrm{D}_{8}(\mathrm{~S}) \mathrm{Smar}$ & - & - & - & - & - & - & - & - & - & - & - & - & - & - & - & - & - & - & - & - & - & - & - & - & - & - & - & - & G & & - & - & - & - \\
\hline $\mathrm{D}_{9}(\mathrm{~S}) \mathrm{Smar} /$ Harash & - & - & - & - & - & - & - & - & - & - & - & - & - & - & - & A & - & - & A & - & A & - & - & - & - & - & $\mathrm{C}$ & $\mathrm{C}$ & G & - & C & C & A & - \\
\hline $\mathrm{D}_{10}(\mathrm{~S})$ Harash & C & - & - & - & - & - & - & - & - & - & - & - & - & - & - & - & - & - & - & $\mathrm{C}$ & - & C & - & - & - & - & C & C & G & - & C & C & A & - \\
\hline $\mathrm{D}_{11}(\mathrm{~S})$ Constantine & & & & & & & & & & & & & & & & - & & & - & & - & C & - & - & - & - & $\mathrm{C}$ & C & G & - & C & C & - & $\mathrm{T}$ \\
\hline $\mathrm{D}_{12}(\mathrm{~S})$ Constantine & - & * & G & G & G & G & C & A & $\mathrm{T}$ & $\mathrm{T}$ & $\mathrm{T}$ & $\mathrm{C}$ & - & & & - & & & - & & - & C & - & - & - & - & $\mathrm{C}$ & C & G & - & C & C & - & $\mathrm{T}$ \\
\hline
\end{tabular}

acetylcholinesterase encoded by the ace-1 gene. Both genes displayed several resistance alleles in eight of the nine studied localities, and the frequency of susceptible individuals, harbouring susceptible alleles on both loci varied between $21 \%$ (in Kala and Guelma) and 100\% (in Douas).

Six of the nine samples display no or low frequency $(\leq 10 \%)$ of resistant Ester allele carriers, suggesting that they appeared recently, most probably by migration (Raymond et al., 1991). In the Western region (Tafna and Zitoun), the frequency of overproduced esterases carriers reached $25-36 \%$, the predominant allele being Ester ${ }^{4}$. Close to the Eastern border (Kala), their frequency reached 28\%, with sster $^{2}$ being predominant. As evolution of insecticide resistance through esterase overproduction appears to proceed by allele replacement rather than by selection of modifiers (Guillemaud et al., 1998; Labbé et al., 2005), this suggests that the

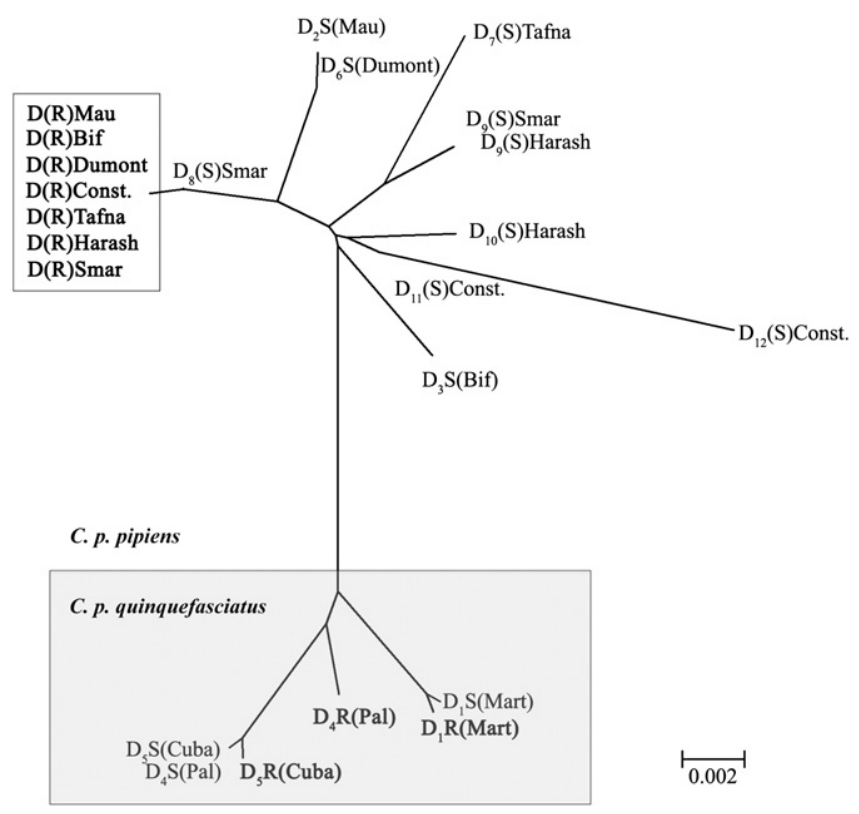

Fig. 2. Genetic distance tree of ace-1 sequences from C. p. pipiens carrying a duplicated haplotype. Sequences of intron 2 and exon 3 were used and G119S mutation was not included in order to consider only "resistance neutral" mutations. $D(R)$ sequences are in bold characters and those of $C$. p. pipiens are included in a square. Samples of $C$. $p$. quinquefasciatus are framed in grey. less frequent alleles may be in the process of being replaced by Ester ${ }^{2}$ in the Eastern region and by Ester ${ }^{4}$ in the Western region. Indeed, the various Ester resistant alleles do not share the same characteristics: both resistance and fitness cost vary quantitatively according to the gene amplification level, and qualitatively according to each allele (Weill et al., 2000; Pasteur et al., 2001; Berticat et al., 2002a,b, 2004; Labbé et al., 2009). Resistance allele frequencies will depend in part on the local intensity and on the nature of insecticide treatments, and in the other part on the fitness of resistant individuals. At selection equilibrium, the most frequent allele would be the most advantageous in the local conditions (i.e. the one providing the best local fitness). For example, in Montpellier area (South of France), the first resistant allele to appear in 1972, Ester ${ }^{1}$, has been replaced by the less costly Ester ${ }^{4}$ allele, after a change in insecticide treatment in 1984 (changing OP insecticides and reducing quantity; see Guillemaud et al., 1998). Ester ${ }^{2}$ appeared later (1991) and seems to be taking over both Ester ${ }^{1}$ and Ester ${ }^{4}$, without any change in insecticide treatment, (Labbé et al., 2005, 2009).

The second resistance mechanism, the insensitive AChE1, was present in almost all samples, and two different mutations (G119S and F290V) were found. Due to the fitness cost associated with the G119S mutation in non-treated areas (Raymond et al., 2001; Berticat et al., 2002a,b, 2004; Duron et al., 2006), its presence indicates that the selection pressure of OP or CX insecticides is (or has been in the recent past) relatively strong in Algeria. In the Zitoun sample, no individual harbouring the G119S AChE1 was detected, whereas the F290V AChE1 was observed in $12 \%$ of the analyzed mosquitoes. The selection of the F290V AChE1 may have been favoured relatively to the G119S AChE1 because it provides higher resistance to specific insecticides (Alout and Weill, 2008; Alout et al., 2009).

Distinct OP insecticides are used in each city independently in Algeria, including methomyl, chlorpyrifos, malathion, parathionmethyl, pyrimiphos-methyl, fenitrothion and dichlorvos; however we failed to obtain more information on local insecticide application procedures. We nevertheless suggest that each local insecticide treatment (nature and quantity) has selected for a particular resistance gene or allele and that the local environmental conditions are probably critical to explain the present distribution of resistance alleles, as stressed out by Labbé et al. (2005). The Algerian situation is in sharp contrast from that observed in Tunisia: mostly one, sometime two resistant alleles co-exist in most Algerian populations, while many distinct resistant Ester and ace-1 alleles co-exist in each Tunisian samples studied so far (Ben Cheikh 
et al., 2009). In Tunisia, a large variety of insecticides is also used (at least chlorpyrifos, temephos, fenitrothion, pyrimiphos-methyl and other insecticide classes such as pyrethroids and Bacillus toxins [Ben Cheikh et al., 2008, 2009]). The difference between the Algerian and the Tunisian situation may be due to the fact that only a single insecticide is used in each Algerian city (or district), compared to a mixture of several insecticides applied at the same time in the Tunisian regions.

Using a genetic test and molecular analyses on four strains derived from field samples, we characterized six distinct duplicated haplotypes containing the G119S mutation (Table 4, Fig. 2). All of them harbour the same $\mathrm{D}(\mathrm{R})$ copy (identical to the R copy present in homozygous [RR] individuals), but it is associated with distinct $\mathrm{D}(\mathrm{S})$ copies, which are different from those already described in France (see Labbé et al., 2007a,b). Moreover, a statistical inference from the ace-1 allele frequencies indicated that the presence of the duplicated ace-1 gene was the most probable hypothesis to explain the excess of [RS] heterozygous ace-1 phenotypes at least in three samples (Guelma, Smar and Harash). The estimated frequency of individuals carrying this D allele (estimated between 21 and $41 \%$ ) is in sharp contrast with the very low frequency of homozygous [RR] mosquitoes $(0-8 \%)$. This is consistent with a better advantage of the duplicated $\mathrm{D}$ allele over the non-duplicated $\mathrm{R}$ allele in the environmental conditions of the studied sites: in treated areas, the selection pressure favours the resistant ace-1 copy of a duplication because the enzyme coded by the susceptible copy is inhibited, while in non-treated areas, the susceptible ace-1 copy most probably restores at least partially the fitness cost associated with the resistant copy (Bourguet et al., 1996; Labbé et al., 2007a,b).

Several mechanisms of duplication have been proposed (for more details see Labbé et al., 2007a). Among the most probable, one involves duplication of the R allele followed by a S119G reversion on one of them, restoring a susceptible $S$ copy; this mechanism would thus result in high similarity between $D(S), D(R)$ and the single $R$ copies. Another mechanism involves an unequal crossing-over in a heterozygous [RS] individuals resulting in $D(R)$ and $D(S)$ copies not more similar than the single $\mathrm{R}$ and $\mathrm{S}$ alleles sampled randomly in the population. Secondary events of recombination may then occur between a duplicated haplotype and a single ace-1 copy or between two duplicated haplotypes, shuffling ace-1 copies in duplicated haplotypes and increasing their variety (Labbé et al., 2007a). In Smar sample, the $D_{8}(S)$ copy differs from the $R$ copy only by the G119S mutation, and may thus result from the first mechanism. For the other duplications, the differences between the $D(S)$ and the $D(R)$ copies would more likely result from the second mechanism.

Interestingly, all duplications share the same resistant $D(R)$ copy, identical also to the single resistant $\mathrm{R}$ allele in C. p. pipiens subspecies (Weill et al., 2003; Labbé et al., 2007a). Then, it is impossible to infer the number of independent duplication events (named duplication sensu stricto by Labbé et al., 2007a) leading to the nine duplicated haplotypes observed in Algerian and French $C$. p. pipiens. Indeed, either multiple duplications sensu stricto of ace-1 gene or a single duplication event followed by multiple secondary recombinations could explain the observed variety of the duplicated haplotypes. We know that at least two duplications sensu stricto probably appeared independently in C. p. pipiens from southern France (Labbé et al., 2007b). It is then also probable that more than one duplication event occurred in Algeria.

Together with the characterization of five other D haplotypes associated with the F290V mutation in the Mediterranean region (Alout et al., 2009), this study reveals a high occurrence of ace-1 duplications in C. p. pipiens. We know from recent studies on human genomes (Korbel et al., 2008) that the number of genes with intraspecific copy number variation can be quite high $\left(10^{-4}-10^{-6}\right.$ per generation) in contrast to previous studies based on interspecific comparisons that estimated the rate of duplication to be of the same magnitude as the rate of mutation per nucleotide site $\left(2 \times 10^{-8}\right.$ per generation; Lynch and Conery, 2000; Gu et al., 2002). Our study of a single gene in $C$. pipiens appears to confirm this high intraspecific rate of duplication.

In conclusion, our survey demonstrated the presence of several insecticide resistant alleles in $C$. p. pipiens mosquitoes in Algeria. Sequence analysis revealed a high occurrence of ace-1 duplications in C. p. pipiens, at least in the Mediterranean region. Although, we could not determine the duplication rate of the ace-1 gene, it seems to be very high. The ace-1 allele frequencies suggest that the duplicated alleles are less costly than the single R allele. They are thus predicted to invade the OP-treated areas. Unfortunately, the cost associated with the non-duplicated $\mathrm{R}$ allele constitutes an asset to manage insecticide resistance since stopping insecticide treatments (or changing nature of insecticides) is probably sufficient to decrease its frequency (Lenormand et al., 1999); by solving the trade-off between fitness cost and resistance, ace-1 duplications might reduce the chances of eliminating AChE1 resistance mechanisms and stress the importance to develop new tools for vector control.

\section{Acknowledgement}

We are very grateful to C. Bernard, and S. Unal for technical assistance and Benharzallah Naouel (Université Mohamed Khider Biskra, Algeria) and B. Alout and A. Benamira for collecting mosquito in Constantine and in the eastern border of Algeria, respectively. This work was financed in part by the ANR Morevol Sante-Environnement (Ministère délégué à la Recherche) and by Comité de Coopération Marseille Provence Méditerranée supervised by Robert Bismuth. All sequence data were obtained on the Environmental Genomic Platform of the IFR Montpellier-Environnement-Biodiversité. Contribution 2010. 109 of the Institut des Sciences de l'Evolution de Montpellier (UMR CNRS 5554).

\section{References}

Alout, H., Berthomieu, A., Hadjivassilis, A., Weill, M., 2007. A new amino-acid substitution in acetylcholinesterase 1 confers insecticide resistance to Culex pipiens mosquitoes from Cyprus. Insect Biochem. Mol. Biol. 37, 41-47.

Alout, H., Djogbenou, L., Berticat, C., Chandre, F., Weill, M., 2008. Comparison of Anopheles gambiae and Culex pipiens acetycholinesterase 1 biochemical properties. Comp. Biochem. Physiol. B Biochem. Mol. Biol. 150, 271-277.

Alout, H., Weill, M., 2008. Amino-acid substitutions in acetylcholinesterase 1 involved in insecticide resistance in mosquitoes. Chem. Biol. Interact. 175, $138-141$.

Alout, H., Labbe, P., Berthomieu, A., Pasteur, N., Weill, M., 2009. Multiple duplications of the rare ace-1 mutation $\mathrm{F} 290 \mathrm{~V}$ in Culex pipiens natural populations. Insect Biochem. Mol. Biol. 39, 884-891.

Ben Cheikh, R., Berticat, C., Berthomieu, A., Pasteur, N., Ben Cheikh, H., Weill, M. 2008. Characterization of a novel high-activity esterase in Tunisian populations of the mosquito Culex pipiens. J. Econ. Entomol. 101, 484-491.

Ben Cheikh, R., Berticat, C., Berthomieu, A., Pasteur, N., Ben Cheikh, H., Weill, M. 2009. Genes conferring resistance to organophosphorus insecticides in Culex pipiens (Diptera: Culicidae) from Tunisia. J. Med. Entomol. 46, 523-530.

Berticat, C., Dubois, M.P., Marquine, M., Chevillon, C., Raymond, M., 2000. A molecular test to identify resistance alleles at the amplified esterases locus in the mosquito Culex pipiens. Pest. Manag. Sci. 56, 727-731.

Berticat, C., Boquien, G., Raymond, M., Chevillon, C., 2002a. Insecticide resistance genes induce a mating competition cost in Culex pipiens mosquitoes. Genet. Res. 79, 41-47.

Berticat, C., Rousset, F., Raymond, M., Berthomieu, A., Weill, M., 2002b. High Wolbachia density in insecticide-resistant mosquitoes. Proc. Biol. Sci. 269, 1413-1416.

Berticat, C., Duron, O., Heyse, D., Raymond, M., 2004. Insecticide resistance genes confer a predation cost on mosquitoes, Culex pipiens. Genet. Res. 83, 189-196.

Bourguet, D., Guillemaud, T., Chevillon, C., Raymond, M., 2004. Fitness costs of insecticide resistance in natural breeding sites of the mosquito Culex pipiens. Evolution 58, 128-135.

Bourguet, D., Raymond, M., Bisset, J., Pasteur, N., Arpagaus, M., 1996. Duplication of the ace.1 locus in Culex pipiens from the Caribbean. Biochem. Genet. 34, 351-362. 
Corpet, F., 1988. Multiple sequence alignment with hierarchical clustering. Nucleic Acids Res. 16, 10881-10890.

Djogbénou, L., Labbé, P., Chandre, F., Pasteur, N., Weill, M., 2009. Ace-1 duplication in Anopheles gambiae: a challenge for malaria control. Malar. J. 8, 70-80.

Duron, O., Labbé, P., Berticat, C., Rousset, F., Guillot, S., Raymond, M., Weill, M., 2006. High Wolbachia density correlates with cost of infection for insecticide resistant Culex pipiens mosquitoes. Evolution 60, 303-314.

Fisher, R.A., 1958. The Genetical Theory of Natural Selection. Dover Publications, New York.

Georghiou, G.P., Metcalf, R.L., Gidden, F.E., 1966. Carbamates-resistance in mosquitoes; selection of Culex pipiens fatiguans Wied (= Culex quinquefasciatus) for resistance to Baygon. WHO 35, 691-708.

Gu, Z.L., Cavalcanti, A., Chen, F.C., Bouman, P., Li, W.H., 2002. Extent of gene duplication in the genomes of Drosophila, nematode, and yeast. Mol. Biol. Evol. 19, 256-262.

Guillemaud, T., Makate, N., Raymond, M., Hirst, B., Callaghan, A., 1997. Esterase gene amplification in Culex pipiens. Insect Mol. Biol. 6, 319-327.

Guillemaud, T., Lenormand, T., Bourguet, D., Chevillon, C., Pasteur, N., Raymond, M., 1998. Evolution of resistance in Culex pipiens: Allele replacement and changing environment. Evolution 52, 443-453.

Haldane, J.B.S., 1932. The causes of evolution. Harper, New York.

Korbel, J.O., Kim, P.M., Chen, X., Urban, A.E., Weissman, S., Snyder, M., Gerstein, M.B., 2008. The current excitement about copy-number variation: how it relates to gene duplications and protein families. Curr. Opin. Struct. Biol. 18, 366-374.

Labbé, P., Lenormand, T., Raymond, M., 2005. On the worldwide spread of an insecticide resistance gene: a role for local selection. J. Evol. Biol. 18, 1471-1484.

Labbé, P., Berthomieu, A., Berticat, C., Alout, H., Raymond, M., Lenormand, T., Weill, M., 2007a. Independent duplications of the acetylcholinesterase gene conferring insecticide resistance in the mosquito Culex pipiens. Mol. Biol. Evol. 14, 1056-1067.

Labbé, P., Berticat, C., Berthomieu, A., Unal, S., Bernard, C., Weill, M., Lenormand, T., 2007b. Forty years of erratic insecticide resistance evolution in the Mosquito Culex pipiens. PLOS Genet. 3, 2190-2199.

Labbé, P., Sidos, N., Raymond, M., Lenormand, T., 2009. Resistance Gene Replacement in the mosquito Culex pipiens: fitness estimation from long-term cline series. Genetics 182, 303-312.

Lenormand, T., Guillemaud, T., Bourguet, D., Raymond, M., 1998a. Evaluating gene flow using selected markers: a case study. Genetics 149, 1383-1392.

Lenormand, T., Guillemaud, T., Bourguet, D., Raymond, M., 1998b. Appearance and sweep of a gene duplication: adaptive response and potential for new functions in the mosquito Culex pipiens. Evolution 52, 1705-1712.

Lenormand, T., Bourguet, D., Guillemaud, T., Raymond, M., 1999. Tracking the evolution of insecticide resistance in the mosquito Culex pipiens. Nature 400, 861-864.
Lenormand, T., Raymond, M., 2000. Analysis of clines with variable selection and variable migration. Am. Nat. 155, 70-82.

Lynch, M., Conery, J.S., 2000. The evolutionary fate and consequences of duplicate genes. Science 290, 1151-1155.

McKenzie, J.A., Game, A.Y., 1987. Diazinon resistance in Lucilia cuprina - mapping of a fitness modifier. Heredity 59, 371-381.

McKenzie, J.A., 1993. Measuring fitness and intergenic interactions: the evolution of resistance to diazinon in Lucilia cuprina. Genetica 90, 227-237.

Pasteur, N., Pasteur, G., Bonhomme, F., Britton-Davidian, J., 1988. Practical Isozyme Genetics. Ellis Horwood Ltd, Chichester, UK.

Pasteur, N., Marquine, M., Hoang, T.H., Nam, V.S., Failloux, A.B., 2001. Overproduced esterases in Culex pipiens quinquefasciatus (Diptera: Culicidae. from Vietnam. J. Med. Entomol. 38, 740-745.

Poirié, M., Raymond, M., Pasteur, N., 1992. Identification of two distinct amplifications of the esterase B locus in Culex pipiens (L.) mosquitoes from Mediterranean countries. Biochem. Genet. 30, 13-26.

Raymond, M., Callaghan, A., Fort, P., Pasteur, N., 1991. Worldwide migration of amplified insecticide resistance genes in mosquitoes. Nature 350, 151-153.

Raymond, M., Berticat, C., Weill, M., Pasteur, N., Chevillon, C., 2001. Insecticide resistance in the mosquito Culex pipiens: what have we learned about adaptation? Genetica 112/113, 287-296.

Rogers, S.O., Bendich, A.J., 1988. Extraction of DNA from plant tissues. In: Gelvin, S.B., Shilperoort, R.A. (Eds.), Plant Molecular Biology Manuel, vol. A6. Kluwer Academic Publishers, Boston, pp. 1-10.

Thomopson, J., Higgins, D., Gibson, T., 1994. ClustalW. Nucleic Acids Res. 22, 4673-4680.

Weill, M., Berticat, C., Raymond, M., Chevillon, C., 2000. Quantitative polymerase chain reaction to estimate the number of amplified esterase genes in insecticide-resistant mosquitoes. Anal. Biochem. 285, 267-270.

Weill, M., Lutfalla, G., Mogensen, K., Chandre, F., Berthomieu, A., Berticat, C., Pasteur, N., Phillips, A., Fort, P., Raymond, M., 2003. Insecticide resistance in mosquito vector. Nature 423, 136-137.

Weill, M., Malcolm, C., Chandre, F., Mogensen, K., Berthomieu, A., Marquine, M., Raymond, M., 2004. The unique mutation in ace-1 giving high insecticide resistance is easily detectable in mosquito vectors. Insect Mol. Biol. 13, 1-7.

Weill, M., Labbe, P., Duron, O., Pasteur, N., Fort, P., Raymond, M., 2005. Insecticide resistance in the mosquito Culex pipiens: towards an understanding of the evolution of ace genes. In: Fellowes, M.D.E., Holloway, G.J., Rolff, J. (Eds.), Insect Evolutionary Ecology. CABI publishing, Oxon (UK).

Yen, J.H., Barr, A.R., 1973. The etiological agent of cytoplasmic incompatibility in Culex pipiens. J. Invert. Pathol. 22, 242-250. 